Research Article

\title{
Determination of Optimal Extrication Location of High Extraction Roadway of Large-Mining-Height Fully Mechanized Face
}

\author{
Xue-bo Zhang $\mathbb{D}^{1,2,3}$ and Ming Yang $\mathbb{D}^{2,3}$ \\ ${ }^{1}$ The Collaborative Innovation Center of Coal Safety Production of Henan Province, Jiaozuo, Henan 454003, China \\ ${ }^{2}$ State Key Laboratory Cultivation Base for Gas Geology and Gas Control, Jiaozuo, Henan 454003, China \\ ${ }^{3}$ Henan Polytechnic University, Jiaozuo, Henan 454003, China
}

Correspondence should be addressed to Ming Yang; Yming2005@163.com

Received 13 April 2018; Accepted 22 October 2018; Published 11 November 2018

Guest Editor: Guo-zhong $\mathrm{Hu}$

Copyright (C) 2018 Xue-bo Zhang and Ming Yang. This is an open access article distributed under the Creative Commons Attribution License, which permits unrestricted use, distribution, and reproduction in any medium, provided the original work is properly cited.

\begin{abstract}
Determining the optimal extrication location of the high extraction roadway can improve the gas extrication effect of highly gassy mine and solve the problem of gas concentration overrun at the upper corner, which is of great significance to safety and efficient mine production. According to the actual situation of mine, the gas gushing amount in the goaf, pressure difference at both ends of the working face, the 3D porosity, and permeability distribution of the caving zone and fissure zone were obtained by field measurement and numerical calculation. Through theoretical calculation, the proper extraction site of a high-position alley was determined. On this basis, the optimal extraction site of a high-position alley was determined by numerical analysis of the gas extraction effect at different sites. The results show that as the perpendicular distance between high-position alley and goaf floor increases, the gas extraction amount increases first and then decreases. The concentration of extraction gas gradually increases, and the increasing trend is gradually diminished. With the increase of the horizontal distance between the air return way and the high-position alley, the gas extraction amount and gas extraction concentration increase first and then decrease. The optimal extraction site of a high-position alley should be $39 \mathrm{~m}$ vertically away from the goaf floor and $30 \mathrm{~m}$ horizontally away from the air return way.
\end{abstract}

\section{Introduction}

Gas disaster has long been a key factor threatening safety mine production of China; in particular, the gas in goaf severely affects the safety condition of coal face [1]. The high suction roadway-based goaf gas extrication technology enjoys advantages including high concentration and large extrication amount of gas, which is widely used in a highly gassy mine as an effective method to reduce gas emission at a high gassy face and prevent gas overrun at the upper corner and air return way $[2,3]$. In addition, the extrication effect of the high suction roadway is closely related with factors such as extrication location of the high suction roadway and sealing quality of the gas drainage hole.
To determine the optimal extrication location of the high suction roadway, researches have conducted large amounts of researches [4-13]. Li Qingbo and Li Wenzhou analyzed the arrangement mechanism, method, and effect of the high suction roadway under specific geological and mining conditions based on the goaf overlying rock movement law and gas flow distribution law [4]. Li et al. introduced a gas relief-pressure controlling technology using the high suction roadway along the primary coal face of a certain high gas mine and analyzed and determined the reasonable arrangement parameters of the high suction roadway along the roof [5]. Li et al. determined the suitable layer for 13-1 high suction roadway of the Xieqiao coal mine through combining theoretical analysis and actual effect investigation [6]. 
Ding et al. and Liu et al. conducted numerical simulation analysis of the high suction roadway-based gas extrication system using the Fluent software and determined the vertical height and oblique position of the high suction roadway $[3,7]$. The combination method of theoretical analysis and numerical simulation has become a current major research approach. However, former scholars never consider permeability distribution and gas discharge source location during numerical simulation, which leads to poor reliability of simulated results. Regarding above problems, this paper determined the actual permeability distribution and gas discharge source location of the Wangzhuang mine 9101 workface as well as reasonable boundary conditions. Moreover, the optimal extrication location of the high suction roadway of the Wangzhuang mine 9101 workface was determined using the combined method of theoretical calculation and numerical simulation.

\section{Test Working Face Profile}

9101 working face is located at the north of the Xiandu agricultural ecological garden of the Xinming village. In the mine, the east of 9101 workface is $81 / 2 \#$ pulley roadway, the west of 9101 workface is $3 \mathrm{D}$ seismic prospecting fault, the south of 9101 workface is 9102 design working face, and the north of 9101 workface connects Jiang river coal pillar. The ground elevation at the site where 9101 workface is located is $903 \mathrm{~m} \sim 917 \mathrm{~m}$, and the workface elevation is $285 \mathrm{~m} \sim 525 \mathrm{~m}$. The workface is arranged along the coal seam, with a slope length of $335 \mathrm{~m}$, transport roadway length of $1404 \mathrm{~m}$, wind roadway length of $1657 \mathrm{~m}$, and $\mathrm{U}$-shaped ventilation. The thickness of the coal seam is $5.85 \mathrm{~m}$, and mean obliquity of the coal seam is $10^{\circ} \mathrm{C}$, which indicates it is a gently inclined coal seam, with mediumhard overburden rocks. The all-roof caving method is adopted as the roof control method.

\section{Goaf Mathematical-Physical Model and Boundary Condition}

3.1. Goaf Mathematical-Physical Model. Assume that the stope fluid is the incompressible fluid, goaf is the isotropous porous medium, and goaf gas flow is in line with the linear permeation law, i.e., Darcy's law [8]; the viscous resistance coefficient and inertial resistance factor remain unchanged at $Z$ direction. According to the above assumption, the mathematical model of goaf air flow mainly includes the mass conservation equation, Navier-Stokes equation, and composition transfer equation.

Mass conservation equation:

$$
\frac{\partial u}{\partial x}+\frac{\partial v}{\partial y}+\frac{\partial w}{\partial z}=0
$$

$$
\begin{aligned}
u \frac{\partial(\rho u)}{\partial x}+v \frac{\partial(\rho u)}{\partial y}+w \frac{\partial(\rho u)}{\partial z}= & \frac{\partial}{\partial x}\left(\mu \frac{\partial u}{\partial x}\right)+\frac{\partial}{\partial y}\left(\mu \frac{\partial u}{\partial y}\right) \\
& +\frac{\partial}{\partial z}\left(\mu \frac{\partial u}{\partial z}\right)-\frac{\partial p}{\partial x}+S_{u} \\
u \frac{\partial(\rho v)}{\partial x}+v \frac{\partial(\rho v)}{\partial y}+w \frac{\partial(\rho v)}{\partial z}= & \frac{\partial}{\partial x}\left(\mu \frac{\partial v}{\partial x}\right)+\frac{\partial}{\partial y}\left(\mu \frac{\partial v}{\partial y}\right) \\
& +\frac{\partial}{\partial z}\left(\mu \frac{\partial v}{\partial z}\right)-\frac{\partial p}{\partial y}+S_{v} \\
\frac{\partial(\rho w)}{\partial x}+v \frac{\partial(\rho w)}{\partial y}+w \frac{\partial(\rho w)}{\partial z}= & \frac{\partial}{\partial x}\left(\mu \frac{\partial w}{\partial x}\right)+\frac{\partial}{\partial y}\left(\mu \frac{\partial w}{\partial y}\right) \\
& +\frac{\partial}{\partial z}\left(\mu \frac{\partial w}{\partial z}\right)-\frac{\partial p}{\partial z}+S_{w}
\end{aligned}
$$

where $\rho$ is the density; $u, v$, and $w$ are the velocity components in the direction of $X, Y$, and $Z$, respectively; $\mu$ is the dynamic viscosity coefficient; $p$ is the pressure on a fluid microelement; and $S_{u}, S_{v}$, and $S_{w}$ are the generalized source terms in the conservation of momentum equation, respectively.

Composition transfer equation:

$$
\begin{aligned}
& \frac{\partial\left(\rho c_{\mathrm{s}} u\right)}{\partial x}+\frac{\partial\left(\rho c_{\mathrm{s}} v\right)}{\partial y}+\frac{\partial\left(\rho c_{\mathrm{s}} w\right)}{\partial z} \\
& =\frac{\partial}{\partial x}\left(D_{\mathrm{s}} \frac{\partial \rho c_{\mathrm{s}}}{\partial x}\right)+\frac{\partial}{\partial y}\left(D_{\mathrm{s}} \frac{\partial \rho c_{\mathrm{s}}}{\partial y}+\right) \frac{\partial}{\partial z}\left(D_{\mathrm{s}} \frac{\partial \rho c_{\mathrm{s}}}{\partial z}\right)+S_{\mathrm{s}}
\end{aligned}
$$

where $c_{s}, \rho c_{s}$, and $D_{s}$ are the volume concentration, mass concentration, and diffusion coefficient of the component $\mathrm{S}$, respectively, and $S_{\mathrm{s}}$ is the formation rate of the microelement.

The standard $k-\varepsilon$ model was used to describe the law of gas turbulent flow in the working face in this paper, and its governing equations are as follows:

$$
\begin{aligned}
& \frac{\partial(\rho k)}{\partial t}+u \frac{\partial(\rho k)}{\partial x}+v \frac{\partial(\rho k)}{\partial y}+w \frac{\partial(\rho k)}{\partial z} \\
& =\frac{\partial}{\partial x}\left(\mu+\frac{\mu_{t}}{\sigma_{k}}\right) \frac{\partial k}{\partial x}+\frac{\partial}{\partial y}\left(\mu+\frac{\mu_{t}}{\sigma_{k}}\right) \frac{\partial k}{\partial y}+\frac{\partial}{\partial z}\left(\mu+\frac{\mu_{t}}{\sigma_{k}}\right) \frac{\partial k}{\partial z} \\
& \quad+\left(\sigma_{k}-\varepsilon\right), \\
& \frac{\partial(\rho \varepsilon)}{\partial t}+u \frac{\partial(\rho \varepsilon)}{\partial x}+v \frac{\partial(\rho \varepsilon)}{\partial y}+w \frac{\partial(\rho \varepsilon)}{\partial z} \\
& =\frac{\partial}{\partial x}\left(\mu+\frac{\mu_{t}}{\sigma_{\varepsilon}}\right) \frac{\partial \varepsilon}{\partial x}+\frac{\partial}{\partial y}\left(\mu+\frac{\mu_{t}}{\sigma_{\varepsilon}}\right) \frac{\partial \varepsilon}{\partial y}+\frac{\partial}{\partial z}\left(\mu+\frac{\mu_{t}}{\sigma_{\varepsilon}}\right) \frac{\partial \varepsilon}{\partial z} \\
& \quad+\left(c_{1} G_{k} \frac{\varepsilon}{k}-c_{2} \rho \frac{\varepsilon^{2}}{k}\right),
\end{aligned}
$$

Navier-Stokes equation: 
where $\sigma_{k}=1.0, \sigma_{\varepsilon}=1.3, c_{1}=1.44, c_{2}=1.92, G_{\mathrm{k}}$ is the generation of turbulent kinetic energy caused by velocity, and $\mu_{\mathrm{t}}$ is the turbulent viscosity.

3.2. Goaf Physical Model. According to the empirical equation, the model can calculate the height range of the caving zone as $17.55 \sim 23.4 \mathrm{~m}$ and the height range of the fissure zone as $49.48 \sim 60.68 \mathrm{~m}$. For the convenience of model establishment and mesh generation, the height of the goaf physical model was determined as $60 \mathrm{~m}$. The dimensions of the workface, goaf, and high suction roadway (arranged along the goaf, located within the fissure zone of roof damage, interiorly dislocated with the air return roadway by certain distance, and supported by the bolting net) were determined according to the actual situation, as shown in Table 1.

Given that the maximum height of the caving zone of 9101 workface is $23.4 \mathrm{~m}$ and the maximum height of the fissure zone is $60.68 \mathrm{~m}$, the high suction roadway will be easily deformed and losing extrication ability if the arrangement height of the high suction roadway is less than $23.4 \mathrm{~m}$; if the distance between the high suction roadway and the goaf floor is too large, the gas permeability of the overlying rock will be poor, and the extrication amount of gas will be less. Therefore, the 5 high suction roadways are set $30 \mathrm{~m}$ horizontally away from the return air roadway, and vertically high above the goaf floor by $25 \mathrm{~m}, 32 \mathrm{~m}, 39 \mathrm{~m}$, $46 \mathrm{~m}$, and $53 \mathrm{~m}$, respectively.

Given that the goaf boundary abscission rate of the high suction roadway side close to the return air roadway was low, no large amounts of channels are formed for gas transport; when the horizontal distance between the high suction roadway and the return air roadway is too large, the goaf caving rocks will be gradually compacted, the abscission rate will be reduced, and goaf gas concentration will be decreased also. Therefore, the 5 high suction roadways are set $39 \mathrm{~m}$ vertically high above the goaf floor, and horizontally away from the return air roadway by $20 \mathrm{~m}, 30 \mathrm{~m}, 40 \mathrm{~m}, 50 \mathrm{~m}$, and $60 \mathrm{~m}$, respectively.

Based on the physical model dimension of the workface and the location arrangement parameters of the high suction roadway, it can determine the workface physical model under the high suction roadway extrication condition, as shown in Figure 1. (Due to the space limit, hereby below only presents the high suction roadway physical model with a horizontal distance of $30 \mathrm{~m}$ and a vertical distance of $39 \mathrm{~m}$ ).

3.3. Setting Boundary Conditions of the Workface. According to the gas emission quantity of Wangzhuang mine 9101 workface during the period of stoping, as well as the goaf permeability distribution law and field test data, the model boundary conditions can be set as follows:

(1) The inlet of the inlet air roadway is the velocity-inlet, with a mean air speed of $2.59 \mathrm{~m} / \mathrm{s}$.

(2) The outlet of the return air roadway is the pressureoutlet, with a differential pressure of $-130 \mathrm{~Pa}$; the outlet of the high suction roadway is the pressure-outlet, with a negative extrication pressure set as $-13 \mathrm{kPa}$.
TABLe 1: Dimension of the 9101 workface physical model.

\begin{tabular}{lccc}
\hline Dimension & \multicolumn{3}{c}{ Name } \\
& Length $(\mathrm{m})$ & Width $(\mathrm{m})$ & Height $(\mathrm{m})$ \\
\hline Workface & 335 & 5 & 5 \\
Goaf & 300 & 335 & 60 \\
High suction roadway & 290 & 4.5 & 3 \\
$\begin{array}{l}\text { Inlet and return air } \\
\text { roadway }\end{array}$ & 30 & 5 & 4.5 \\
\hline
\end{tabular}

(3) Goaf gas is emitted from the floor, lower neighboring coal seam, and surrounding rock, wherein the gas emission quantity is predicted as $28.33 \mathrm{~m}^{3} / \mathrm{min}$ using a different-source forecast method.

(4) Goaf permeability: analyze the overlying rock property, mining method, and support form of Wangzhuang mine 9101 workface. Simulate the deformation condition of the goaf overlying rock using UDEC numerical simulation software. Conduct comparative analysis of deflections of rock stratums. The 3D porosity distribution laws of the caving zone and the fissure zone of Wangzhuang mine 9101 workface can be obtained according to the porosity calculation equation (as shown by Formulas (5)-(9). During Fluent simulation, goaf porosity and permeability were written using UDF function.

$$
\begin{aligned}
n= & \begin{cases}\frac{h_{1}-12.5}{h_{1}} ; & z \leq h_{1}, \\
\frac{h_{2}-h_{1}-5.8}{h_{2}-h_{1}} ; & h_{1}<z \leq h_{2}, \\
\frac{h_{3}-h_{2}-8}{h_{3}-h_{2}} ; & h_{2}<z \leq h_{3}, \\
\frac{h_{4}-h_{3}-3.8}{h_{4}-h_{3}} ; \quad z>h_{3},\end{cases} \\
h_{1}= & 18.7+\left(0.08972 e^{0.01998(300-x)-3.397}-4.198\right) \\
& \times\left(a_{1} y^{4}+b_{1} y^{3}+c_{1} y^{2}+d_{1} y+0.8641\right), \\
h_{2}= & 23.6+\left(0.03324 e^{0.01892(300-x)-1.782}-3.122\right) \\
& \times\left(a_{2} y^{4}+b_{2} y^{3}+c_{2} y^{2}+d_{2} y+0.4094\right), \\
h_{3}= & 31+\left(0.04821 e^{0.0161(300-x)-1.094}-2.465\right) \\
& \times\left(a_{3} y^{4}+b_{3} y^{3}+c_{3} y^{2}+d_{3} y+0.0013\right), \\
h_{4}= & 34.95+\left(0.04821 e^{0.0161(300-x)-1.094}-2.465\right) \\
& \times\left(a_{3} y^{4}+b_{3} y^{3}+c_{3} y^{2}+d_{3} y+0.0013\right),
\end{aligned}
$$

where $a_{1}=-1.855 e-10, b_{1}=1.244 e-7, c_{1}=-3.125 e-5$; $d_{1}=3.480 e-3 ; a_{2}=-7.594 e-10, b_{2}=5.098 e-7, c_{2}=$ $-1.286 e-4, d_{2}=1.443 e-2$; and $a_{3}=-6.752 e-10$, $b_{3}=4.527 e-7, c_{3}=-1.313 e-4$, and $d_{3}=1.8590 e-2$. 


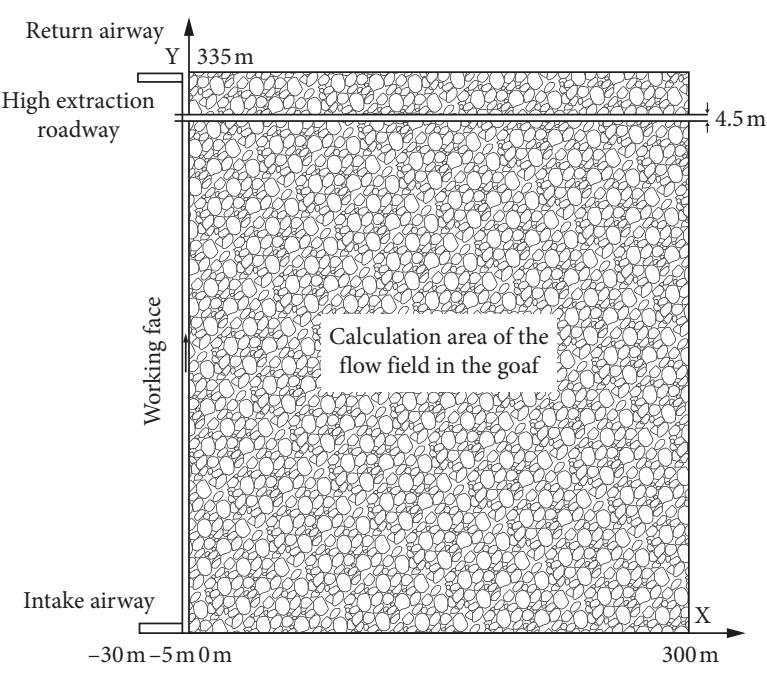

(a)

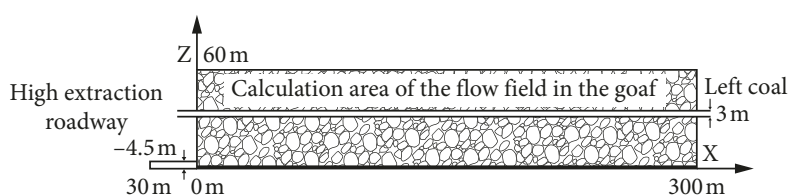

(b)

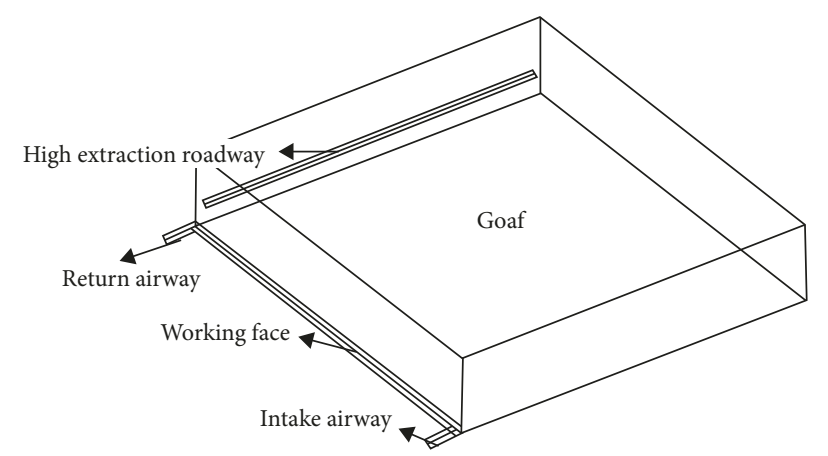

(c)

FIgURE 1: Goaf physical model of fully mechanized face.

\section{Determination of the Optimal Extrication Location of the High Suction Roadway}

\subsection{Determination of the Optimal Vertical Distance between the High Suction Roadway and the Goaf Floor}

4.1.1. Vertical Distance between the High Suction Roadway and the Goaf Floor by Theoretical Calculation. The vertical distance between the high suction roadway and the goaf floor is related to the mining method, overlying rock property, and coal bed pitch. According to Table 2, it can approximately calculate the location of the high suction roadway at the vertical direction [9].

As shown in Table 2, the coal seam thickness of Wangzhuang mine 9101 workface is $5.85 \mathrm{~m}$; the average coal bed pitch is $10^{\circ} \mathrm{C}$, showing that it is a coal seam with gentle dip; the overlying rock is moderately hard, and the all-roof caving method is adopted as the major roof management method. The ratio of the moderate arrangement height of the high suction roadway and the mine height is $5 \sim 12$, which means the suitable arrangement height of the high suction roadway is $29.25 \mathrm{~m} \sim 70.2 \mathrm{~m}$. However, as this range of height is too large, which should be subjected to the numerical simulation method to finally determine the vertical distance between the high suction roadway and the goaf floor.

\subsubsection{Determination of the Optimal Vertical Distance be-} tween the High Suction Roadway and the Goaf Floor. Based on the reasonable physical model and boundary conditions, the gas extrication effect was simulated using Fluent software under constant horizontal distance between the high suction roadway and the return air roadway, and the vertical distance between the high suction roadway and the goaf floor is $25 \mathrm{~m}, 32 \mathrm{~m}, 39 \mathrm{~m}, 46 \mathrm{~m}$, and $53 \mathrm{~m}$, respectively. The concentration and scalar of the extricated gas are shown in Figure 2.
Through analyzing Figure 2, it can be concluded that when the horizontal distance between the high suction roadway and the return air roadway is constant, the scalar of extricate gas first increases and then decreases with the increase of the vertical distance between the high suction roadway and the goaf floor and reaches the largest value of $16.74 \mathrm{~m}^{3} / \mathrm{min}$ when the vertical distance is $39 \mathrm{~m}$. After the vertical distance between the high suction roadway and the goaf floor is larger than $39 \mathrm{~m}$, the increasing tendency of the gas concentration significantly decreases. Based on theoretical calculation, the suitable arrangement height of the high suction roadway is $29.25 \mathrm{~m} \sim 70.2 \mathrm{~m}$, and the vertical distance between the high suction roadway and the goaf floor is $39 \mathrm{~m}$ which is within the theoretical calculation range. The application of the high suction roadway is to extricate more goaf gas of high concentration and reduce gas emission quantity at the upper corner, so as to solve the problem of gas overturn, and use high concentration gas to generate electricity. According to such a principle, it can be determined that the optimal vertical distance between the high suction roadway and the goaf floor is $39 \mathrm{~m}$, and in this situation the gas concentration at the upper corner is $0.732 \%$, which is an underspecified value of $1 \%$ prescribed in the coal mine safety rules.

\subsection{Determination of the Optimal Horizontal Distance between the High Suction Roadway and the Return Air Roadway}

4.2.1. Determination of the Horizontal Distance between the High Suction Roadway and the Return Air Roadway by Theoretical Calculation. In setting the distance between the high suction roadway and the return air roadway, i.e., horizontal projection distance, the high suction roadway should be located within the fissure zone after sufficient pressure relief, and also the high suction roadway should not 
TABLE 2: Moderate arrangement height of the high suction roadway.

\begin{tabular}{lccc}
\hline Coal bed pitch & Overlying rock hardness & Roof management method & $\begin{array}{c}\text { Ratio of moderate arrangement height and } \\
\text { mining height }(H / M)\end{array}$ \\
\hline Gentle dip & Hard & All roof caving & $6 \sim 18$ \\
Gentle dip & Medium hard & All roof caving & $5 \sim 12$ \\
Gentle dip & Soft & All roof caving & $3 \sim 9$ \\
Gentle dip & Weathering soft & All roof caving & $2 \sim 7$ \\
Moderate dip & Medium hard & All roof caving & $5 \sim 12$ \\
Steep dip & Hard & All roof caving & $7 \sim 16$ \\
Steep dip & Medium hard & All roof caving & $5 \sim 6$ \\
Steep dip & Medium hard & Filling & - \\
\hline
\end{tabular}

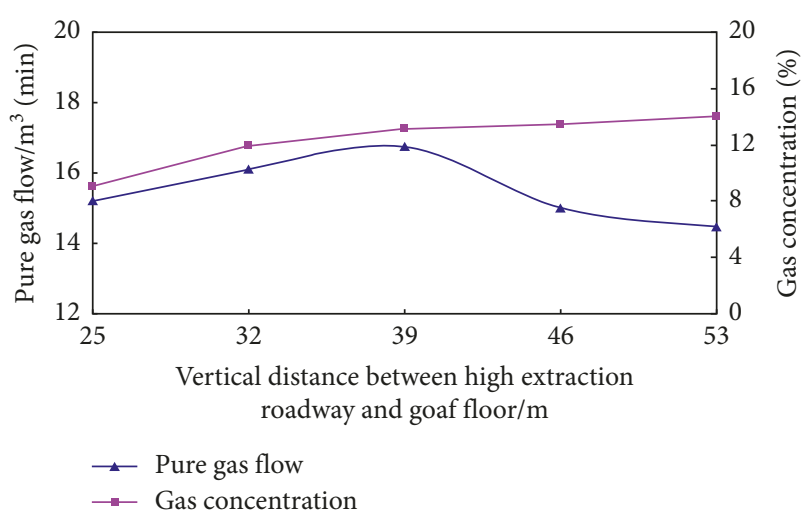

Figure 2: Extrication effect under different vertical distances between the high extraction roadway and the goaf floor.

be damaged. In addition, the horizontal projection distance should not exceed $1 / 3$ of the stope face length, as shown in Figure 3, which can be calculated as follows:

$$
\begin{aligned}
S & =\Delta L+L^{\prime}, \\
\Delta L & =\frac{1}{3} \times\left(X / 3-L^{\prime}\right), \\
L & =\frac{H}{\operatorname{tg} \beta}, \\
L^{\prime} & =\frac{H}{\operatorname{tg} \alpha},
\end{aligned}
$$

where $S$ is the horizontal projection distance between the high suction roadway and the return air roadway, $m ; \Delta L$ is the boundary distance of the high suction roadway after sufficient pressure relief, $\mathrm{m}$; $L^{\prime}$ is the horizontal projection length which guarantees that the high suction roadway is not damaged, $m ; L$ is the horizontal projection length away from the return air roadway without pressure relief, $m$; $\mathrm{X}$ is the workface length, $m$; $\alpha$ is the roof rock collapse angle, $68^{\circ}$; and $\beta$ is the pressure-relief angle of the roof rock, which is generally larger than the collapse angle by $3^{\circ} \sim 4^{\circ}$.

Using the above equations, it can be calculated that the vertical distance between the high suction roadway and the goaf floor is $39 \mathrm{~m}$, the horizontal projection length $L^{\prime}$ which guarantees that the high suction roadway is not damaged is $15.76 \mathrm{~m}$, and the boundary distance of the high suction roadway $\Delta L$ after sufficient pressure relief is $31.99 \mathrm{~m}$.

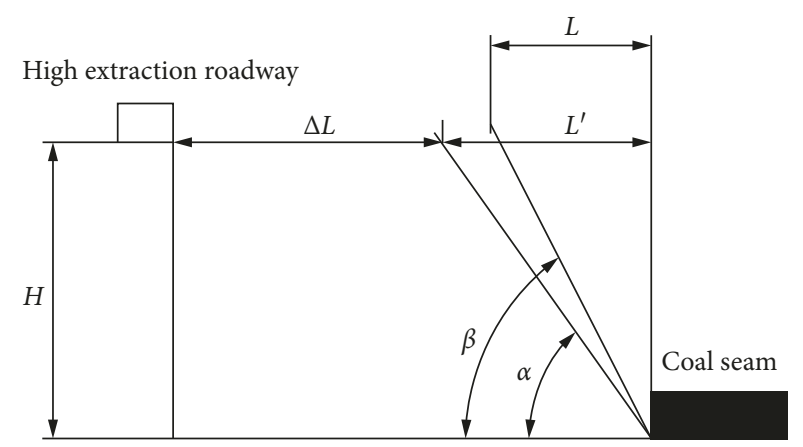

Figure 3: Profile perspective drawing of high suction roadway arrangement.

In addition, the horizontal projection distance between the high suction roadway and the return air roadway is $111.67 \mathrm{~m}$, which does not exceed $1 / 3$ of the workface length. The horizontal projection distance range between the high suction roadway and the return air roadway is $15.76 \mathrm{~m} \sim$ $111.67 \mathrm{~m}$. However, such a range is too large and should be subjected to the numerical simulation method to further determine the horizontal distance between the high suction roadway and the return air roadway.

\subsubsection{Determination of the Optimal Horizontal Distance} between the High Suction Roadway and the Return Air Roadway. Based on the reasonable physical model and boundary conditions, the gas extrication effect was simulated using Fluent software under constant vertical distance between the high suction roadway and the goaf floor, and the horizontal distance between the high suction roadway and the goaf floor is $20 \mathrm{~m}, 30 \mathrm{~m}, 40 \mathrm{~m}, 50 \mathrm{~m}$, and $60 \mathrm{~m}$, respectively. The concentration and scalar of the extricated gas are shown in Figure 4.

Through analyzing Figure 4, it can be concluded that when the vertical distance between the high suction roadway and the return air roadway is constant, both scalar and concentration of extricate gas first increase and then decrease with the increase of the horizontal distance between the high suction roadway and the return air roadway and reach the largest value of $16.74 \mathrm{~m}^{3} / \mathrm{min}$ and $13.20 \%$ when the horizontal distance is $30 \mathrm{~m}$. After the vertical distance between the high suction roadway and the goaf floor is larger than $39 \mathrm{~m}$, the horizontal projection distance range between 


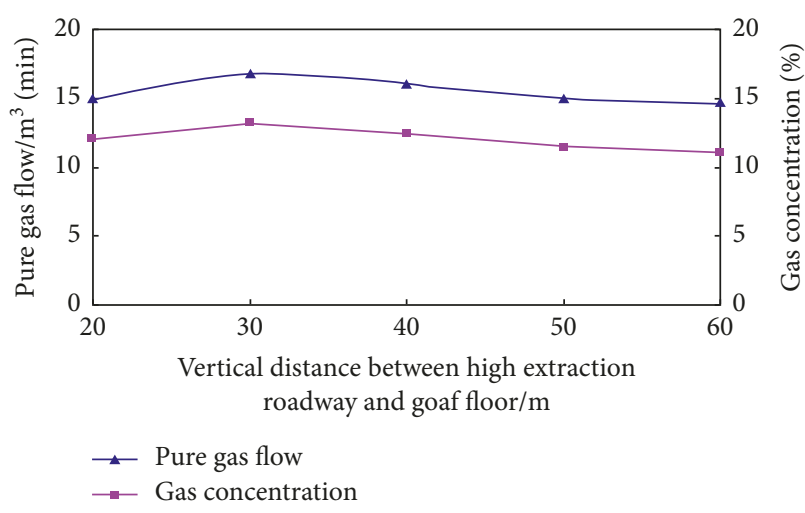

FIGURE 4: Extrication effect of the high extraction roadway under different horizontal distances between the high extraction roadway and the return air roadway.

the high suction roadway and the return air roadway is from $15.76 \mathrm{~m}$ to $111.67 \mathrm{~m}$, and the horizontal distance between the high suction roadway and the return air roadway is $30 \mathrm{~m}$, which is within the theoretical calculation range. The application of the high suction roadway is to extricate more goaf gas of high concentration and reduce gas emission quantity at the upper corner, so as to solve the problem of gas overturn, and use high concentration gas to generate electricity. According to such a principle, it can be determined that the optimal horizontal distance between the high suction roadway and the return air roadway is $30 \mathrm{~m}$, and in this situation the gas concentration at the upper corner is $0.732 \%$, which is an underspecified value of $1 \%$ prescribed in the coal mine safety rules.

\section{Field Verification}

The high extraction roadway of Wangzhuang mine 9101 workface was laid out according to the data. Gas drainage data of the high extraction roadway were monitored in June 2013. The gas extraction concentration is $11.4 \% \sim 13 \%$, and the average value is $12.28 \%$; the average gas concentration in the upper corner is $0.69 \%$. Therefore, the field test results are in good agreement with the numerical simulation results. It also verifies the correctness of the numerical simulation method and results.

\section{Conclusions}

(1) The scalar of gas extricated by the high suction roadway first increases and then decreases with the increase of the vertical distance between the high suction roadway and the goaf floor and reaches its maximum value of $16.74 \mathrm{~m}^{3} / \mathrm{min}$ when the vertical distance is $39 \mathrm{~m}$; the concentration of the extricated gas is gradually increasing; however, the increasing trend will be significantly decreased after the vertical distance between the high suction roadway and the goaf floor is larger than $39 \mathrm{~m}$.

(2) Both scalar and concentration of the gas extricated by the high suction roadway first increase and then decrease with the increase of the horizontal distance between the high suction roadway and the goaf floor and reach their maximum values of $16.74 \mathrm{~m}^{3} / \mathrm{min}$ and $13.20 \%$ when the horizontal distance is $30 \mathrm{~m}$.

(3) Combining the theoretical calculation results and numerical simulation results, it can be concluded that the optimal extrication location for the high suction roadway of Wangzhuang mine 9101 workface is vertically $39 \mathrm{~m}$ above from the goaf floor and horizontally $30 \mathrm{~m}$ away from the return air roadway.

\section{Data Availability}

The data used to support the findings of this study are available from the corresponding author upon request.

\section{Conflicts of Interest}

The authors declare that they have no conflicts of interest.

\section{Acknowledgments}

This work was supported by the National Natural Science Foundation of China (Grant nos. 51734007, 51704099, and 51604101), the Henan Province Basic and Frontier Technology Research Projects of China (Grant No. 142300413233), Key Scientific Research Projects in Colleges and Universities in Henan (Grant No. 19A440003), and the Opening Foundation of State Key Laboratory Cultivation Base for Gas Geology and Gas Control (Grant No. WS2017B14).

\section{References}

[1] C. Wang, "Optimization of extrication parameters of gas extricated by strike high-bleeding roadway in dafosi coal mine," M.A. thesis, Department Safety Engineering, Xi'an University of Science and Technology, Xi'an, China, 2012.

[2] X. Li, "Comparative and case study of high location drilling field goaf gas extrication and high suction roadway goaf gas extrication," Safety in Coal Mines, vol. 42, no. 5, pp. 122-125, 2011.

[3] H. Ding and C. Ma, "Numerical simulation and test analysis of goaf gas extrication by strike high-bleeding roadway," Journal of Safety Science and Technology, vol. 8, no. 5, pp. 5-10, 2012.

[4] Q. Li and W. Li, "Optimized design and analysis of high suction roadway arrangement," Coal Mining Technology, vol. 15, no. 5, pp. 28-30, 2010.

[5] Y. Li, W. Zheng, and F. Wang, "Analysis of gas extrication effect by high suction roadway along roof strike," Mining Safety and Environmental Protection, vol. 40, no. 3, pp. 74-76, 2013.

[6] Q. Li, D. Li, M. Li et al., "Determination of optimal location of high suction roadway of 13-1 workface of Xieqiao coal mine," Mining Science and Technology, vol. 39, no. 2, pp. 24-26, 2011.

[7] R. Liu and J. Zhang, "Study of gas extrication technology based on strike high-bleeding roadway," China Mining Magazine, vol. 21, no. 1, pp. 122-124, 2012.

[8] M. Yang, , J. Gao, and P. Feng, "Numerical simulation of goaf gas distribution with U-shape and Y-shape ventilation," Journal of Safety and Environment, vol. 12, no. 5, pp. 227-230, 2012. 
[9] T. Tang, S. Li et al., "Extrication of gas in coal seam group using high suction roadway and up-hole drill," Mineral Engineering Reseach, vol. 27, no. 1, pp. 21-25, 2012.

[10] D. Y. Li, J. Wang, S. Wang et al., "Reasonable position determination of highly-located gas drainage roadway of longwall panel 12070 in Shoushan no. 1 coal mine," Journal of Henan Polytechnic University (Natural Science), vol. 37, no. 5, pp. 1-7, 2018.

[11] S. Wang, "Application of gas extraction technology in highlevel drainage roadway along driving directions," China Energy and Environmental Protection, vol. 40, no. 6, pp. 20-25, 2018.

[12] C. Kang, "Numerical simulation of gas drainage effect to high drainage roadway," Journal of Shanxi Institute of Energy, vol. 31, no. 4, pp. 39-41, 2018.

[13] H. Gao, "Position arrangement of high level gas drainage roadway and investigation on the gas drainage effect in Zhaozhuang Coal Mine," Coal Engineering, vol. 50, no. 3, pp. 8-11, 2018. 


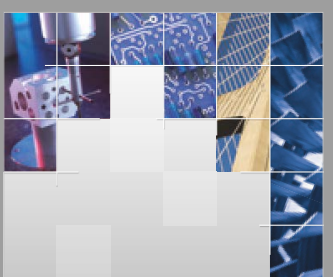

\section{Enfincering}
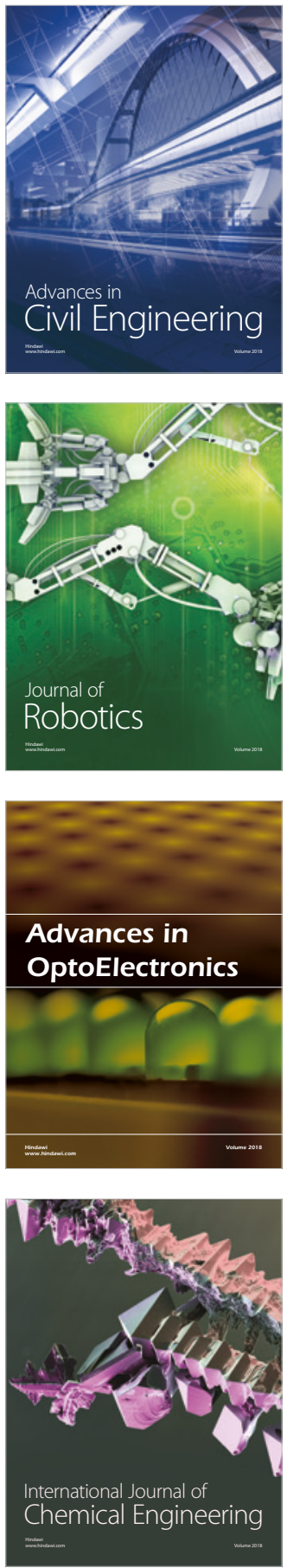

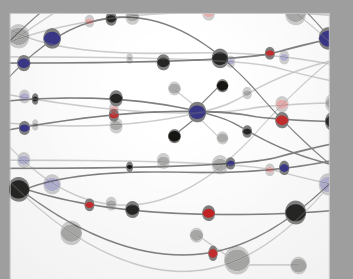

\section{Rotating \\ Machinery}

The Scientific World Journal

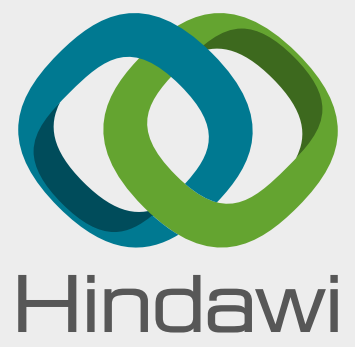

Submit your manuscripts at

www.hindawi.com
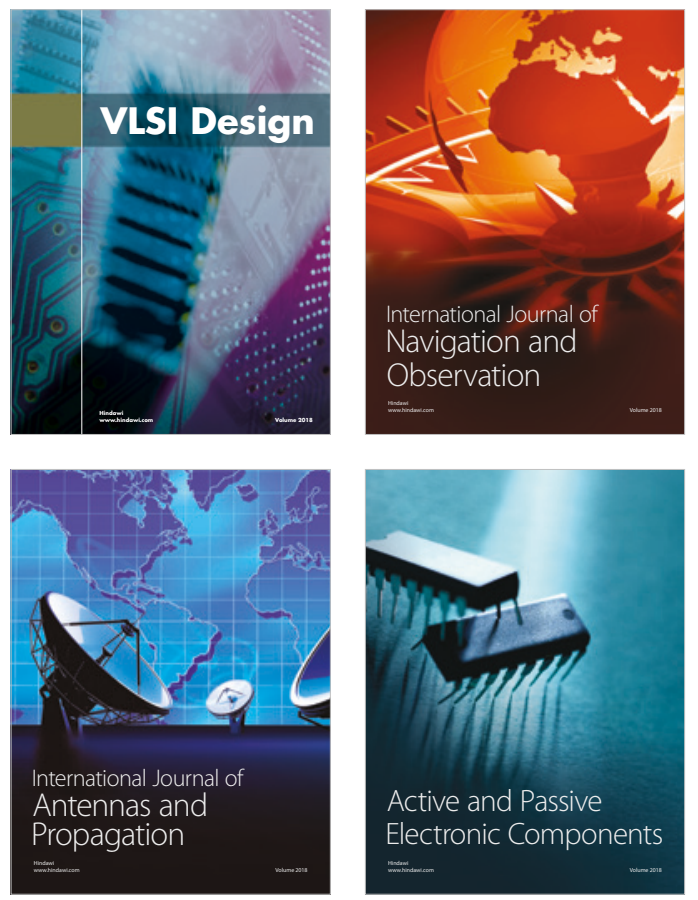
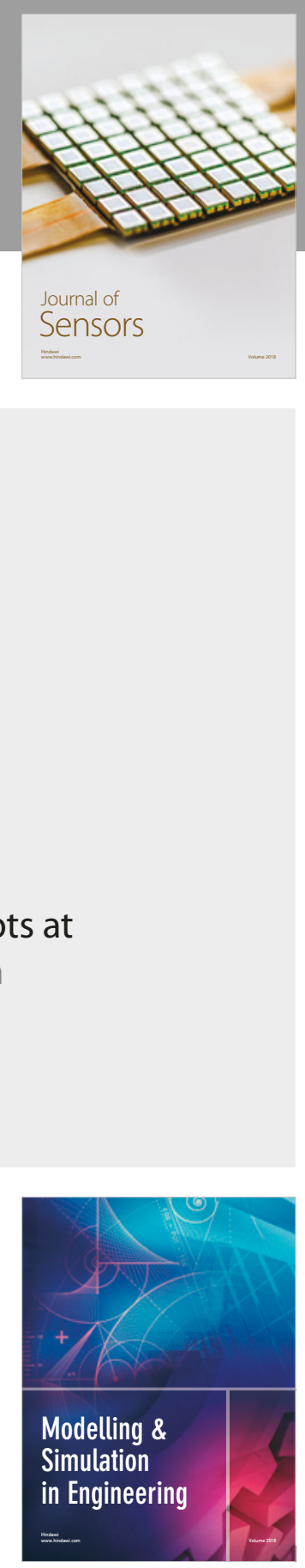

\section{Advances \\ Multimedia}
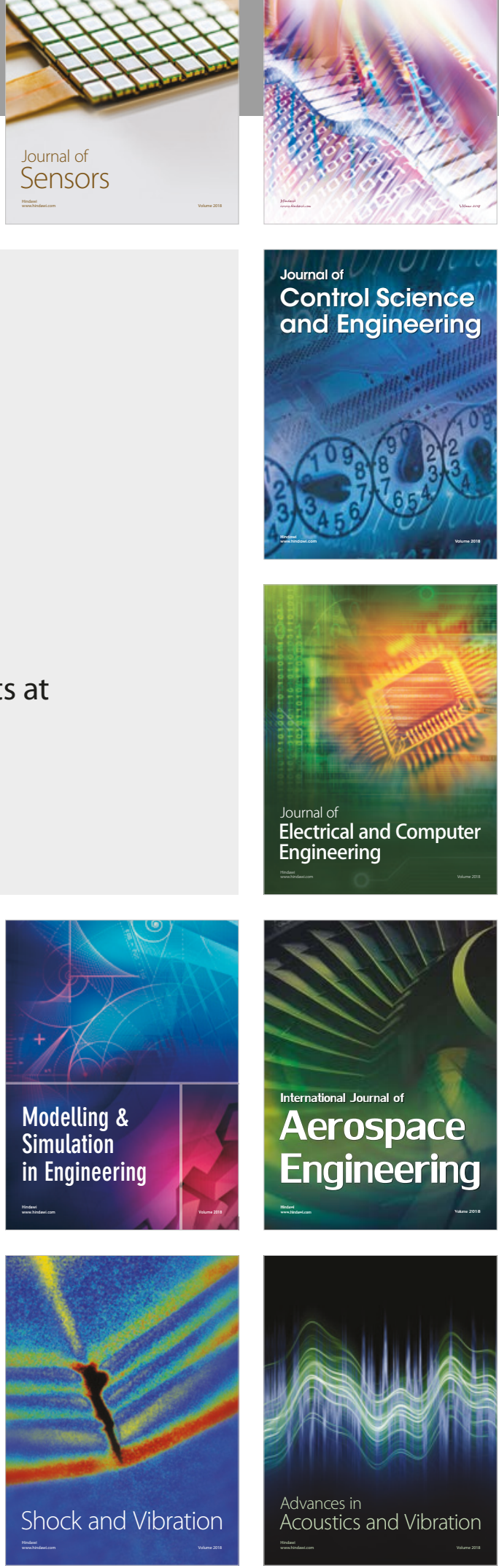